\title{
MEASURING INSTRUCTOR'S READINESS ON ACCEPTING THE USE OF E-LEARNING SYSTEM DURING COVID-19 PANDEMIC IN HIGHER EDUCATION OF KUWAIT
}

\author{
Anwaar Alkandari, Kuwait Technical College, Kuwait \\ Aisha Alseddiqi, The Public Authority for Applied Education and Training, Kuwait \\ Ahmad R. Alsaber, University of Strathclyde, Glasgow, Scotland
}

dx.doi.org/10.18374/JABE-21-2.3

\begin{abstract}
E-learning has arisen as a need to face the obstacles raised by Covid-19's current circumstance and IT growth and the capacity for greater access to information. The decision to close all educational institutions, including public and private universities, is among the difficulties faced by the State of Kuwait during the Corona pandemic. There were appeals and claims to carry out the e-learning process separately. However, several obstacles affect the implementation of e-learning in higher education. Whether various stakeholders in higher education institutions prefer to accept or oppose e-learning for their work needs to be understood. This study explores the readiness of instructors in Kuwait's higher education institutions to carry out the process of e-learning. The key purpose of this report is to evaluate Kuwait's universities instructors' readiness. To realize this research target, the e-learning literature was studied, and an exploratory analysis was performed in Kuwait. Then a conceptual model was proposed based on TAM's technological preparation model and amended with the findings of e-learning literature analysis to measure the e-learning acceptance. The initial conceptual model was developed to research e-learning readiness in Kuwait. Quantitative analysis approach was used to analyze and test the conceptual construct. Conducted a questionnaire web-based. This report ends by highlighting research's key results.
\end{abstract}

Keywords: E-learning, Readiness, Technology Readiness, Technology Acceptance Model (TAM) 